\title{
Effect of ethical leadership and climate on effectiveness
}

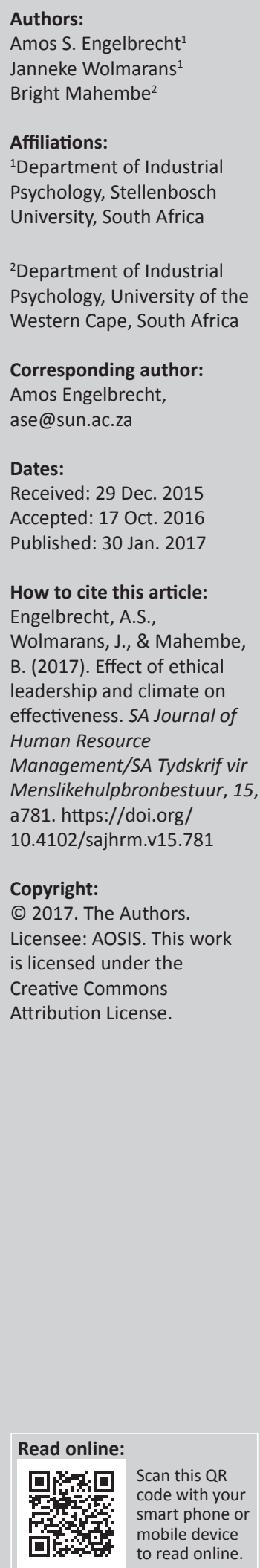

Orientation: The increasing prevalence of theft, sabotage and other deviant behaviours in the workplace has disastrous effects for organisations, such as lowered effectiveness, escalated costs and the organisation's declining reputation.

Research purpose: The purpose of the research was to design and investigate the relationships among perceived leader effectiveness, ethical climate and ethical leadership. A further objective of the investigation was to validate a conceptual model clarifying the structural associations among the latent constructs in the South African corporate domain.

Motivation for the study: A successful leader is both an ethical and an effective leader. An organisation's leadership is seen as the most critical element in establishing and maintaining an ethical climate in organisations.

Research design, approach and method: A convenient and multi-cultural sample comprised of 224 employees from various organisations in South Africa. The structure and content of the variables were analysed through confirmatory factor analysis (CFA), beside item analysis.

Main findings: Satisfactory reliability was found for all the measurement scales. The results of CFA demonstrated acceptable fit with the data for the refined measurement and structural models. The results of structural equation modelling (SEM) indicated positive relationships among ethical leadership, ethical climate and leader effectiveness.

Practical implications: Organisational leaders should take full responsibility for cultivating ethics through ethical leader behaviour and an ethical climate. By reinforcing these aspects, perceived leader effectiveness can be advanced, which will ultimately decrease corruption and other forms of counterproductive behaviour in South African organisations.

Contribution: The study provides further theoretical and empirical evidence that leadership effectiveness can be realised through instilling an ethical organisational climate in which ethical leadership is exhibited and encouraged.

\section{Introduction}

South African organisations are characterised by accelerated counterproductive behaviour (e.g. corruption, crime, anarchy and the threatening of the social framework of the communities) (Van Zyl, 2012). Van Zyl (2012) furthermore stated that the South African corporate sector, in particular, has been confronted increasingly with an absence of recognised moral norms in their procedures. Negative outcomes that unethical behaviour sustains for individuals, organisations and the broader South African economy necessitate an emphasis on the factors that may have an effect on ethical behaviour (Engelbrecht, Heine \& Mahembe, 2014; Naidoo, 2012; Lloyd \& May, 2010).

Ethical behaviour is becoming more essential, with organisations beginning to realise its importance (Lloyd \& May, 2010; Mayer, Aquino, Greenbaum \& Kuenzi, 2012). Lloyd and May (2010) acknowledged that to improve their productivity, organisations need to incorporate ethics in their decisions. An organisation's leadership is seen as the most critical element in creating, establishing and maintaining an ethical organisational culture (Eisenbeiss, 2012; Kalshoven, Den Hartog \& De Hoogh, 2011; Kuntz, Kuntz, Elenkov \& Nabirukhina, 2013). To develop an ethical culture, the leader should play a significant role in the development of the ethical strategy, convey the ethical code of behaviour and lead by example pertaining to principled leadership.

In addition, Naidoo (2012) asserted that effective leadership can minimise cases of corruption in South African organisations. Successful leadership provides a predominant sense of 
guidance and vision, an orientation with the environment, a useful means for innovation and creativity, and a resource for revitalising the organisational culture. Unethical leadership in South African organisations includes corruption, insensitivity to the needs of customers, slowness in the performance of tasks and manifestations of ineffectiveness and inefficiency (Mafunisa, 2008; Naidoo, 2012). These researchers suggested that leader effectiveness in organisations can be affected by placing greater emphasis on accountability, responsibility, transparency and adhering to rules and procedures (Mafunisa, 2008; Naidoo, 2012).

\section{Aim of the study}

Continuous ethical misconduct in today's world of work results in astronomic financial losses to organisations on an annual basis (Nasir \& Bashir, 2012; Van Zyl, 2012). Dysfunctional consequences of unethical and counterproductive work behaviour consequently raise questions about why deviant behaviour occurs in organisations and what role effective organisational leaders can play in managing this behaviour. This raises the need to investigate the emerging role effective leaders play in shaping ethical employee behaviour (Appelbaum \& Shapiro, 2006; Brown, Treviño \& Harrison, 2005; Nasir \& Bashir, 2012).

An effective leader has a responsibility to create and develop an environment in which followers can excel. Ciulla (1995) furthermore argued that a successful leader is both an effective and moral leader. Organisational leaders should be central sources of ethical behaviour because employees look to them for direction (Brown et al., 2005). Effective ethical leaders consequently have a considerable influence on the ethical behaviour of employees (Eisenbeiss, 2012; Kalshoven et al., 2011; Yukl, 2013; Zhu, Avolio, Riggio \& Sosik, 2011).

To fully explore the emergence of unethical practices, one needs to understand the difference between effective leaders and less effective leaders to differentiate between ethical and unethical leaders. The question one should ask is why some individuals are effective as ethical leaders, while others fail. The question that initiated this study therefore concerned; why variance exists in leader effectiveness, with specific reference to the role that ethical climate and ethical leadership play in this regard, but not to the exclusion of other factors in the organisation.

\section{The relationships between ethical climate and leader effectiveness}

An ethical climate can be seen as a mechanism to oppose counterproductive work behaviour. The invisible ground rules of ethical climates protect organisations against pressures, opportunities and predispositions that entice employees into unethical behaviour (Sims, 1992). Organisations with strong ethical climates communicate norms clearly in terms of moral issues to their employees
(Bartels, Harrick, Martell \& Strickland, 1998). An organisation that comprises a strong ethical climate is not a random occurrence. Why is it then that some organisations contain stronger ethical climates than others?

The incidence of an ethics code does not automatically ensure moral conduct. It is essential, however, that the practice of creating and conveying the ethics code to all interested parties occurs in a participative and transparent way (Lloyd \& May, 2010; Rossouw \& Van Vuuren, 2010). It is essential furthermore to make certain that the code is implemented throughout the organisation. Treviño and Neslon (as cited in Lloyd \& May, 2010) asserted that the unsuccessful implementation of the ethics code will lead to it missing its legality and being seen as impression management. It has been proposed that the extent to which formal ethics codes are insisted on and abided by in an organisation depends largely on the perceived legitimacy of these codes, the linkage between the codes and the practices of the organisation (e.g. performance management procedures), and mainly on the existence of effective leadership to demonstrate and motivate appropriate behaviours (Kuntz et al., 2013). Leadership is inherently attached to issues of ethics and can hence be seen as a contributing factor in the manifestation of strong ethical climates (Eubanks, Brown \& Ybema, 2012). Several studies have investigated the role of leaders in establishing ethical climates (Dickson, Smith, Grojean \& Ehrhart, 2001; Grojean, Resick, Dickson \& Smith, 2004; Simha \& Cullen, 2011).

Leaders influence the performance of employees and prohibit certain unwanted behaviour in the workplace (Henning, Theron \& Spangenberg, 2004). Leaders may elicit or block out the tendencies of organisational members to behave in an unethical or ethical manner. Individuals are hence more likely to act in unethical ways when justification for unethical behaviour is presented by a legitimate authority or organisational figure. Positive perceptions of leaders' ethical conduct can therefore be regarded as pivotal for the development of an ethical climate which embodies the organisation's vision and norms (Brown, 2007; Pimental, Kuntz \& Elenkov, 2010).

In addition, comprehensive models of leadership have identified key variables to explain effective leadership behaviour. In the framework for describing leader effectiveness, one such model contained the organisation context (i.e. climate) as a major variable (Harshman \& Harshman, 2008). Consequently, the efficiency of leadership in inhibiting unethical behaviours may be realised through the process of improving an employee's perception of the work environment, which can be instilled because of the leader's stimulation of a moral culture (Mayer, Kuenzi \& Greenbaum, 2010; Neubert, Carlson, Kacmar, Roberts \& Chonko, 2009). It can therefore be postulated that the moral culture of an organisation has a positive influence on the perceived effectiveness of the leader. 


\section{The relationship between ethical leadership and leader effectiveness}

Employees, from a social learning perspective, are anticipated to identify with, have a high regard for, and imitate their ethical leaders and perceive them as examples of acceptable behaviour (Bandura, 1986; Brown et al., 2005). Such role models are likely to be perceived as effective (Kalshoven \& Den Hartog, 2009).

Ethical leaders are perceived as appealing, authentic and reliable role models that engage in morally acceptable behaviour and make the ethics meaning noticeable and influence employee outcomes. Leaders cannot anticipate moral behaviour from subordinates if they do not act morally themselves. Owing to the fact that ethical leaders are seen by their followers as legitimate and attractive role models who gain and retain their attention, they have a more effective influence on their followers. Over the years, attributes of ethical leaders such as openness, consideration and fairness have been considered fundamental to perceived leader effectiveness (Brown et al., 2005; Yukl, 2013). Employees will generally be more satisfied with leaders who discipline wrongdoers, who treat followers fairly and considerately, and who are trustworthy (Brown et al., 2005). Furthermore, specific morality-linked communication and encouragement can be seen to contribute to the significance of the leader's moral initiatives (Brown et al., 2005).

Brown et al. (2005) and De Hoogh and Den Hartog (2008) discovered positive relationships between moral leadership and observed leader success. Effective leaders function in a successful manner and try to meet the work-related needs of the followers. This suggests that ethical leaders direct employees toward responsible goals, which advance the organisation and its employees (Kanungo, 2001).

Ethical leaders feel highly responsible for their actions, and it can be expected that followers will perceive them as effective (Kalshoven et al., 2011). In general, it can be assumed that ethical leaders will usually be regarded by their followers as successful. It could hence be proposed that ethical leadership has a positive impact on leader effectiveness in an organisation.

\section{The relationship between ethical leadership and ethical climate}

Victor and Cullen (1988, p. 101) conceptualised ethical climate as 'the prevailing perceptions of typical organisational practices and procedures that have ethical content'. Organisational cultural factors (including leadership and reward systems that support ethical behaviour, fair dealing with employees, ethics integrated in regular managerial decision-making and a caring for employees) all contributed to ethics-related attitudes and behaviours (Brown \& Treviño, 2006).
From a social learning perspective, Brown and Treviño (2006) proposed that stronger ethical climates support the development and sustaining of ethical leadership in organisations. Such organisations provide more formal policies and informal norms that support ethical behaviour and advancement of ethical conduct. In such environments, leaders have more chances to imitate models of ethical leadership, and they realise that ethical leadership is desirable and appropriate.

Ethical leaders' behaviour can be seen as a critical determinant of an organisation's ethical climate. An organisation's ethical climate should therefore be representative of the leader's dedication to moral values and norms conveyed in their daily effort to conduct themselves accordingly (Engelbrecht, Van Aswegen \& Theron, 2005; Kanungo \& Mendonca, 1996). Ethical leaders who have intense individual viewpoints on the necessity for moral behaviour will positively influence an ethical climate (Engelbrecht et al., 2005). An ethical leader additionally provides signals about what is ethical by overtly rewarding and punishing certain behaviours (Brown \& Treviño, 2006). An ethical leader consequently determines the organisational climate, through the development of organisational policies and practices (Eubanks et al., 2012; Mayer et al., 2010). From the above assumptions and findings, it can be postulated that ethical leadership has a positive influence on an ethical climate in an organisation.

\section{Conceptual model}

In accordance with the literature study and theoretical opinions discussed before, a conceptual model was developed indicating the hypothesised relationships among ethical leadership, ethical climate and leader effectiveness. Ethical leadership is depicted as the exogenous or independent variable, whereas ethical climate and leader effectiveness are shown as dependent or endogenous variables. The conceptual model, demonstrated in Figure 1, indicates the different linkages among the various latent variables.

\section{Hypotheses}

- Hypothesis 1: The overarching substantive research hypothesis was deduced to show that the conceptual model in Figure 1 presents an ideal description of the psychological process that determines the effect of ethical leadership on ethical climate and leader effectiveness.

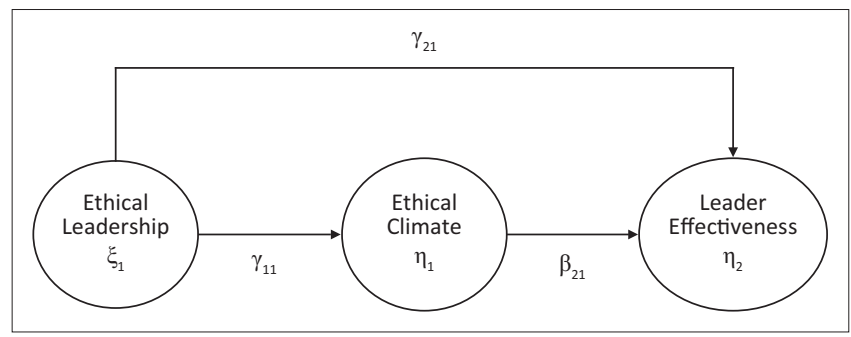

FIGURE 1: The structural model representing the relationships between ethical leadership, ethical climate and perceived leader effectiveness. 
The substantive hypothesis was consequently translated into the following exact fit null hypothesis:

- $\mathrm{H}_{01}$ : Root mean square error of approximation $($ RMSEA) $=0$

- $\mathrm{H}_{\mathrm{a} 1}$ : RMSEA > 0

- Hypothesis 2: If the overarching substantive hypothesis as depicted by the structural model presents an approximate account of the variance as exhibited in leader effectiveness, the substantive hypothesis could be translated to the following close fit hypothesis:

- $\mathrm{H}_{02}:$ RMSEA $\leq 0.05$

- $\mathrm{H}_{\mathrm{a} 2}:$ RMSEA $>0.05$

The overarching substantive research hypothesis was separated into three more explicit substantive research hypotheses. The three detailed research hypotheses translate into the path coefficient statistical hypotheses:

- Hypothesis 3: A significant positive relationship exists between ethical climate $\left(\eta_{1}\right)$ and leader effectiveness $\left(\eta_{2}\right)$ :

- $\mathrm{H}_{03}: \beta_{21}=0$

- $\mathrm{H}_{\mathrm{a} 3}: \beta_{21}>0$

- Hypothesis 4: A significant positive relationship exists between ethical leadership $\left(\xi_{1}\right)$ and leader effectiveness $\left(\eta_{2}\right)$ :

- $\mathrm{H}_{04}: \gamma_{21}=0$

- $\mathrm{H}_{\mathrm{a} 4}: \gamma_{21}>0$

- Hypothesis 5: A significant positive relationship exists between ethical leadership $\left(\xi_{1}\right)$ and ethical climate $\left(\eta_{1}\right)$ :

- $\mathrm{H}_{05}: \gamma_{11}=0$

- $\mathrm{H}_{\mathrm{a} 5}: \gamma_{11}>0$.

\section{Research methodology Sample}

A non-probability convenience sampling technique was employed in this investigation. The sample comprised of 224 employees working in different organisations in South Africa. The sample comprised of 159 males (71\%) and 65 females (29\%). The sample presented an average age of 29.58 years. The race division was as follows: black $(75 \%)$, mixed race $(6.7 \%)$, Indian $(2.7 \%)$, white $(14.7 \%)$ and other $(0.9 \%)$. The majority of respondents came from nonmanagerial (64.3\%) and lower-level management (21.4\%) and mainly from the retail industry (97\%).

A questionnaire developed to collect data was distributed via the Internet and was sent off to the obtained respondents. Data were also collected by means of paper-and-pencil tests, which were distributed to employees who did not have Internet access.

\section{Ethical considerations}

Respondents were expected to agree to the requirements stipulated in the directions for the questionnaire. Informed consent was obtained from the respondents. Participants were assured that confidentiality would be maintained by treating their responses as anonymous and that no names would be disclosed. Informed institutional permission for the research was attained from the organisations that were participating in the study. The Research Ethics Committee of Stellenbosch University furthermore granted approval for the ethical clearance of the study.

\section{Measuring instruments}

Three measures were utilised to assess the variables of ethical climate, ethical leadership and perceived leader effectiveness.

\section{Perceived leader effectiveness}

A 5-item Leader Effectiveness Questionnaire (LEQ) was developed for the aim of this research. Three items were revised from Bass and Avolio's (1994) Multifactor Leadership Questionnaire (MLQ). The items in the LEQ focus on motivating team performance beyond expectations, meeting team objectives, effective team representation by the leader, team members' satisfaction with their leader and followers' perceived overall effectiveness of the leader (Bass \& Avolio, 1994; Hui, Chiu, Yu, Cheng \& Tse, 2007; Yukl, 2013).

\section{Ethical climate}

Ethical climate in the organisations was measured by the 19-item Ethical Climate Questionnaire (ECQ) of Victor and Cullen (1988). The internal consistencies (Cronbach's alpha) of the four subscales of the ECQ were as follows: the Caring, Law and Rules subscales all had high alpha coefficients $(0.92,0.88$ and 0.85 , respectively) (Victor \& Cullen, 1988). The Independence $(\alpha=0.69)$ subscale was relatively lower, yet sufficient for establishing internal consistency (Nunnally, 1978).

\section{Ethical leadership}

Ethical leadership was assessed through the 17-item Leadership of Ethics Scale (LES). The LES was designed by Engelbrecht (Engelbrecht et al., 2014). The LES was constructed on items from various scales of ethical leadership (Brown et al., 2005, nine items; Mayer et al., 2012, one item; Spangenberg \& Theron, 2005, three items; Yukl, Mahsud, Hassan \& Prussia, 2011, four items).

The LES measures the extent to which the leader treats his or her followers with respect, acting fairly, rewarding ethical conduct, emphasising an ethical vision and transferring ethical leadership into the organisation

The LES has high reliability and was assessed and confirmed through exploratory factor analysis (EFA) and confirmatory factor analysis (CFA) (Engelbrecht et al., 2014). The Cronbach's alpha of the LES was reported to be 0.97, indicating a high level of internal consistency (Nunnally, 1978).

EFA confirmed the uni-dimensionality of the LES. All 17 items in the LES loaded satisfactory $(>0.50)$ on the single underlying factor. The measurement model fits the data well and the quality of the fit is good (Engelbrecht et al., 2014). 


\section{Research results Missing values}

The data in this research met the conditions set by Mels (2003) for the utilisation of the multiple imputation method, namely, that the perceived constructs should be assessed on a scale consisting of five or above scale points, the latent variables should not be too skewed (although the null hypothesis of multivariate normality had been rejected) and fewer than $30 \%$ of the data should represent missing values.

\section{Reliability analysis}

SPSS (Version 23) was utilised to carry out item analysis on all three measures to confirm whether the instrument was consistent with regard to measures of the specific scales in question. The summary of the reliability results for each measurement scale can be seen in Table 1. All scales attained reliability scores that surpassed the suggested criterion of 0.70. The findings furthermore revealed that all items produced an item-total correlation exceeding the suggested criterion value (0.30). All measurement scales could hence be considered reliable instruments for gathering information to test the hypotheses.

\section{Evaluating the measurement models}

The next section reports an outline of the goodness-of-fit indices (GFIs) attained from the confirmatory factor analyses executed on every measurement model achieved from the statistics of the respondents $(n=224)$. Different indicators were deduced to determine the goodness of fit of the measurement model. In general, a good model fit with the data was obtained.

TABLE 1: Reliability of measurement scales.

\begin{tabular}{|c|c|c|}
\hline Scale & Cronbach's alpha & Number of items \\
\hline $\begin{array}{l}\text { Leader Effectiveness } \\
\text { Questionnaire }\end{array}$ & 0.843 & 5 \\
\hline $\begin{array}{l}\text { Ethical Climate } \\
\text { Questionnaire: Caring }\end{array}$ & 0.848 & 7 \\
\hline $\begin{array}{l}\text { Ethical Climate } \\
\text { Questionnaire: Law }\end{array}$ & 0.792 & 4 \\
\hline $\begin{array}{l}\text { Ethical Climate } \\
\text { Questionnaire: Rules }\end{array}$ & 0.709 & 4 \\
\hline $\begin{array}{l}\text { Ethical Climate } \\
\text { Questionnaire: } \\
\text { Independence }\end{array}$ & 0.840 & 4 \\
\hline $\begin{array}{l}\text { Total Ethical Climate } \\
\text { Questionnaire }\end{array}$ & 0.892 & 19 \\
\hline Leadership of Ethics Scale & 0.949 & 17 \\
\hline
\end{tabular}

\section{Goodness of fit: The Leader Effectiveness Questionnaire measurement model}

In terms of the absolute fit indices of the LEQ as reported in Table 2, an acceptable model fit had been achieved (RMSEA < 0.08) (Diamantopoulos \& Siguaw, 2000). Based on the $p$-value test of close fit (RMSEA < 0.05), the LEQ obtained a value indicative of good fit $(p>0.05)$ (Diamantopoulos \& Siguaw, 2000). The standardised root mean residual (SRMR) value was $<0.05$, which indicated good fit. The GFI exceeded 0.9, which indicated that the model showed good absolute fit. The incremental fit indices (normed fit index, NFI and comparative fit index, CFI) surpassed the criterion ratio of 0.90. Thus, the model indicated a good incremental fit. The null hypothesis of exact fit $\left[\mathrm{H}_{0}: \Sigma=\Sigma(\theta)\right]$, as well as the null hypothesis of close fit $\left(\mathrm{H}_{0}\right.$ : RMSEA $\left.\leq 0.05\right)$, was not rejected. The measurement model for leader effectiveness thus showed both close and exact fit. It means that the measurement model accomplished an acceptable fit with the data, in that the model reproduced the observed sample covariance matrix and provided a credible explanation of the observed covariance matrix.

\section{Goodness of fit: The Ethical Climate Questionnaire measurement model}

The following conclusions were drawn in terms of the ECQ. Based on large modification indices found, two items from the Caring subscale and one item from the Rules subscale were deleted. An analysis of the indicators shown in Table 2 implied that the revised model of the ECQ presented good fit with the data. The model achieved good fit in terms of the $p$-value test of close fit $(>0.05)$ and the RMSEA $(<0.05)$. The null hypothesis of close fit was not declined, indicating that the measurement model of the ECQ fits the data well and can reproduce the observed sample covariance matrix. The SRMR value was not below the 0.05 threshold and indicated relatively poor model fit. The GFI value for the measurement model was 0.90 , which demonstrated that the model showed good absolute fit.

The incremental fit indices (NFI and CFI) exceeded the critical value of 0.90 , which was satisfactory. The model therefore indicated good incremental fit.

\section{Goodness of fit: The Leadership of Ethics Scale measurement model}

The GFIs for the LES, as reported in Table 2, indicated that satisfactory fit had been achieved. The null hypothesis of exact fit was declined, whereas the null hypothesis of close fit was not declined. Another concern was that the GFI failed to exceed the 0.90 criterion, indicating good fit. However,

TABLE 2: Goodness-of-fit indices for the measurement and structural models.

\begin{tabular}{|c|c|c|c|c|c|c|c|c|}
\hline Model & $\mathrm{S}-\mathrm{B} \chi^{2}$ & $d f$ & RMSEA & $p_{\text {close fit }}$ & SRMR & GFI & NFI & CFI \\
\hline LEQ & 9.18 & 5 & 0.06 & 0.32 & 0.04 & 0.97 & 0.99 & 0.99 \\
\hline ECQ & $141.78^{*}$ & 98 & 0.045 & 0.693 & 0.075 & 0.90 & 0.96 & 0.99 \\
\hline LES & $173.029 *$ & 119 & 0.045 & 0.699 & 0.04 & 0.89 & 0.98 & 0.99 \\
\hline SMODEL & 1599.479* & 699 & 0.076 & 0.00 & 0.076 & 0.68 & 0.93 & 0.96 \\
\hline
\end{tabular}

S-BX $x^{2}$, Satorra-Bentler scaled chi-square; $d f$, degrees of freedom; RMSEA, root mean square error of approximation; $p_{\text {close fit }} p$-value for test of close fit (RMSEA $<0.05$ ); SRMR, standardised root mean residual; GFI, goodness-of-fit index; NFI, normed fit index; CFI, comparative fit index; LEQ, Leader Effectiveness Questionnaire; ECQ, Ethical Climate Questionnaire; LES, Leadership of Ethics Scale; SMODEL, structural model.

$*, p<0.05$ 
the RMSEA and the SRMR values indicate good fit. In terms of the incremental fit measures, the measurement model indicates good fit.

\section{Goodness-of-fit indices for the structural mode}

A summary of the most fundamental GFI indicators for the conceptual model is shown in Table 2. Through a comprehensive inspection of all of the fit indices, it can be assumed that the structural model fits the data well. With reference to the findings of the absolute fit indicators, the Satorra-Bentler scaled chi-square statistic for the structural model, however, suggested that there was not an exact fit with the data $(p<0.001)$. In the light of the RMSEA index, the structural model achieved reasonable fit. The obtained $p$-value for the test of close fit did not support the assumption of good fit. Consequently, the null hypotheses of exact and close fit were rejected. The reported SRMR and the obtained GFI marginally missed the criteria of good fit. With reference to the incremental fit measures, it was found that the structural model attained NFI and CFI indices that were $>0.90$, indicating good comparative fit.

To ensure a comprehensive validation of the conceptual model, it was furthermore important to analyse the modification indicators to verify the degree to which the model explicated the observed covariance among the latent variables. An inspection of the modification indicators of the structural model implied that no supplementary linkages among any of the manifest variables would substantially enhance the fit of the postulated conceptual model.

\section{The relationship between the latent variables}

An investigation of the latent variables was required to establish whether the relationships postulated at the theorising phase were confirmed by the results.

\section{The relationship between ethical climate and leader effectiveness}

The SEM results revealed a significant path coefficient $(t=3.071, p<0.05)$ between ethical climate and leader effectiveness, which led to the rejection of the null hypothesis. Consequently, it can be assumed that the postulated positive relationship between these two constructs was confirmed.

The positive association between ethical climate and leader effectiveness has frequently been reported in previous studies (Dickson et al., 2001; Eubanks et al., 2012; Grojean et al., 2004; Simha \& Cullen, 2011). Kuntz et al. (2013) suggested that the enforcement of formal ethics codes in an organisation depends largely on the presence of effective leadership to model and reinforce desirable behaviours.

Brown (2007) considered positive perceptions of a leader's ethical conduct as pivotal for the development of an ethical climate. This perception can be instilled through the leader's promotion of an ethical climate as leaders have a direct effect on subordinates' views of an ethical climate (Mayer et al., 2010; Neubert et al., 2009).

\section{The relationship between ethical leadership and leader effectiveness}

A positive relationship was obtained between ethical leadership and leader effectiveness $(t=4.681, p<0.05)$. This consequently led to the rejection of the null hypothesis. It can therefore be concluded that the postulated relationship between these two constructs was confirmed in the current research.

The support obtained for the positive association between ethical leadership and leader effectiveness is also portrayed in the literature (Brown et al., 2005; De Hoogh \& Den Hartog, 2008; Kalshoven \& Den Hartog, 2009).

\section{The relationship between ethical leadership and ethical climate}

Statistical support was found for a positive association between ethical leadership and ethical climate $(t=7.637$, $p<0.05)$. A significant linkage was found in the model and the null hypothesis could therefore be declined.

The findings confirmed the positive relationship between these variables found in the literature (Eubanks et al., 2012; Grojean et al., 2004; Mayer et al., 2010).

\section{Discussion}

The results confirmed the postulated relationships in the structural model (Figure 1). Positive relationships were found between ethical leadership and ethical climate, ethical leadership and leader effectiveness, and ethical climate and leader effectiveness. The results imply that ethical leaders can have a positive influence on the development of an organisation's ethical climate. An ethical leader can determine the ethical climate through the development and implementation of ethical organisational policies and practices. It thus seems that followers would perceive their organisational climate as ethical if they can see that their leader is ethical and consistent in his or her leadership role. Ethical leaders' behaviour can hence be seen as a critical determinant of an ethical climate in organisations.

The results furthermore indicate that ethical leaders can have a positive effect on the followers' perception of the effectiveness of their leaders. Employees who can identify with, respect and imitate their leader's behaviour, perceive them as role models of ethical and appropriate behaviour and are likely to view such a leader as more effective (Bandura, 1986; Kalshoven \& Den Hartog, 2009; Kalshoven et al., 2011). Consequently, ethical leaders have a more effective influence on their followers. Employees will be more satisfied with leaders who are trustworthy and treat them fairly and considerately.

In addition, the results reveal that an ethical climate in an organisation can have a positive effect on the followers' perception of the effectiveness of their leaders. Leaders who are seen as effective leaders are those who develop and 
promote an ethical organisational climate through developing an ethical vision for the organisation, communicating formal ethical codes of conduct to all stakeholders, developing and implementing an ethical policy, reinforcing ethical behaviour and who are role models of ethical conduct.

\section{Limitations of the study and suggestions for future research}

Some shortcomings to this research may be identified. Firstly, the theoretical model was evaluated on a non-probability convenience sample, and it cannot be claimed to be representative of the target population. It is recommended that the validity of the model also be analysed in a crossvalidation investigation on a different sample in other industries. It is furthermore recommended that a longitudinal study of the postulated structural model be undertaken to facilitate further convincing causal deductions.

The second shortcoming relates to the problem of common method bias because the data were collected at a specific date utilising only self-reported scales (Donaldson \& GrantVallone, 2002). When supporting the findings of this study, future research should hence consider utilising data from multiple sources to address this issue.

The third limitation concerns the fact that the structural model might have excluded other significant determinants of leader effectiveness. Future studies could explore other mediating and moderating variables (e.g. trust, organisational justice, work engagement and organisational citizenship behaviour) to further clarify the relationship between ethical leadership and leader effectiveness.

\section{Managerial implications}

Employees reporting to ethical leaders might be more satisfied with their leaders and have a tendency to view their organisations as successful. Ethical leadership augments views of ethical climate, which furthermore incites job satisfaction and commitment (Johnson, Shelton \& Yates, 2012; Neubert et al., 2009).

Leaders can also establish apparent norms and strategies for handling ethical concerns (e.g. establishing ethical codes of conduct) and provide advice on dealing with ethical issues. They can initiate discussions on ethical issues and reinforce ethical behaviour by including it in the criteria for rewarding performance. The leader can also help to mediate conflicts in a way that is consistent with ethical standards. It is appropriate to look for an integrative solution, but even if one cannot be found, it is still desirable to promote trust, fairness and mutual respect among the actions (Yukl, 2013). Leaders should clarify ethical dimensions of management decisions. Leaders should also commit to ethical principles through their influence on corporate culture and create a high degree of congruence, contributing to the ethical climate of the organisation (Spangenberg \& Theron, 2005).
It is expected that the findings of the study will have several suggestions for the live out of ethical leadership in organisations. Through the results, the study emphasises the importance of ethical leadership as an important path to leadership success. The study encourages organisational leaders to improve the performance of their followers and their organisations by making ethics a precedence through modelling moral behaviour, demonstrating caring for employees, reflecting integrity behaviour, setting an irrefutable example, making ethics messages prominent and rewarding ethical behaviour (Johnson et al., 2012). Lastly, the findings attempt to empirically justify why behaving ethically is not only the appropriate thing to do, but how it can additionally improve an organisation's productivity and ultimately increase its profitability (Johnson et al., 2012).

\section{Conclusion}

Unethical employee behaviour is a reality in South African organisations, but through this study it has been discovered that effective leadership can minimise the prevalence of these unwanted behaviour. Organisational leaders should hence take full responsibility for cultivating an ethical climate through ethical leader behaviour. By reinforcing these aspects, perceived leader effectiveness can be advanced among employees, which will ultimately effect overall organisational performance.

\section{Acknowledgements Competing interests}

The authors declare that they have no financial or personal relationships that may have inappropriately influenced them in writing this article.

\section{Authors' contributions}

A.S.E. was the project leader responsible for initiating the conceptualisation of the study, for developing the LEQ and LES, and the primary author of the article. J.W. collected the data and was also responsible for the write-up of the article. B.M. helped with the statistical analyses and interpretation of the results.

\section{References}

Appelbaum, S.H., \& Shapiro, B.T. (2006). Diagnosis and remedies for deviant workplace behaviours. The Journal of American Academy of Business, 9(2), 14-20.

Bandura, A. (1986). Social foundation of thought and action. Englewood Cliffs, NJ: Prentice-Hall.

Bartels, L.K., Harrick, E., Martell, K.M., \& Strickland, D. (1998). The relationship between ethical climate and ethical problems within human resource management. Journal of Business Ethics, 17, 799-804. https://dx.doi. org/10.1023/A:1005817401688

Bass, B.M., \& Avolio, B.J. (1994). Improving organisational effectiveness through transformational leadership. Thousand Oaks, CA: Sage Publications.

Brown, M.E. (2007). Misconceptions of ethical leadership: How to avoid potential pitfalls. Organizational Dynamics, 36(2), 140-155. https://dx.doi.org/10.1016/j. orgdyn.2007.03.003

Brown, M.E., \& Trevino, L.K. (2006). Ethical leadership: A review and future directions. The Leadership Quarterly, 17, 595-616. https://dx.doi.org/10.1016/j. leaqua.2006.10.004 
Brown, M.E., Treviño, L.K., \& Harrison, D. (2005). Ethical leadership: A social learning perspective for construct development and testing. Organizational Behaviour and perspective for construct development and testing. Organizational Behaviour and
Human Decision Processes, 97, 117-134. https://dx.doi.org/10.1016/j. Human Decision
obhdp.2005.03.002

Ciulla, J.B. (1995). Leadership ethics: Mapping the territory. Business Ethics Quarterly, 5(1), 5-28. https://dx.doi.org/10.2307/3857269

De Hoogh, A.H.B., \& Den Hartog, D.N. (2008). Ethical and despotic leadership, relationships with leader's social responsibility, top management team effectiveness and subordinates' optimism: A multi-method study. The Leadership Quarterly, 19, 297-311. https://dx.doi.org/10.1016/j.leaqua.2008.03.002

Diamantopoulos, A., \& Siguaw, J.A. (2000). Introducing LISREL. London: Sage Publications.

Dickson, M.W., Smith, D.B., Grojean, M.W., \& Ehrhart, M. (2001). An organisational climate regarding ethics: The outcome of leader values and practices that reflect them. The Leadership Quarterly, 12, 197-217. https://dx.doi.org/10.1016/S1048 9843(01)00069-8

Donaldson, S.I., \& Grant-Vallone, E.J. (2002). Understanding self-report bias in organisational behaviour research. Journal of Business and Psychology, 17 245-260. https://dx.doi.org/10.1023/A:1019637632584

Eisenbeiss, S.A. (2012). Re-thinking ethical leadership: An interdisciplinary integrative approach. The Leadership Quarterly, 23(6), 791-808. https://dx.doi.org/10.1016/j. leaqua.2012.03.001

Engelbrecht, A.S., Heine, G., \& Mahembe, B. (2014). The influence of ethical leadership on trust and work engagement: An exploratory study. SA Journal of Industrial Psychology, 40(1), 1-9. https://dx.doi.org/10.4102/sajip.v40i1.1210

Engelbrecht, A.S., Van Aswegen, A.S., \& Theron, C.C. (2005). The effect of ethica values on transformational leadership and ethical climate in organisations. South African Journal of Business Management, 36(2), 19-26.

Eubanks, D.L., Brown, A.D., \& Ybema, S. (2012). Leadership, identity and ethics. Journal of Business Ethics, 107(1), 1-3. https://dx.doi.org/10.1007/s10551-012 1295-5

Grojean, M.W., Resick, C.J., Dickson, M.W., \& Smith, D.B. (2004). Leaders, values, and organizational climate: Examining leadership strategies for establishing an organizational climate regarding ethics. Journal of Business Ethics, 55(3), 223-241. https://dx.doi.org/10.1007/s10551-004-1275-5

Harshman, C.L., \& Harshman, E.F. (2008). The Gordian knot of ethics: Understanding leadership effectiveness and ethical behaviour. Journal of Business Ethics, 78(1/2), 175-192. https://dx.doi.org/10.1007/s10551-006-9318-8

Henning, R., Theron, C.C., \& Spangenberg, H.H. (2004). An investigation into the internal structure of the unit performance construct as measured by the Performance structure of the unit performance construct as measured by the $\mathrm{P}$
Index (PI). South African Journal of Industrial Psychology, 30(2), 26-36.

Hui, C.H., Chiu, W.C.K., Yu, P.L.H., Cheng, K., \& Tse, H.H.M. (2007). The effects of service climate and the effective leadership behaviour of supervisors on
frontline employee service quality: A multi-level analysis. Journal of Occupational and Organisational Psychology, 80, 151-172. https://dx.doi. Occupational and Organisational
org/10.1348/096317905X89391

Johnson, C.E., Shelton, P.M., \& Yates, L. (2012). Nice guys (and gals) finish first: Ethical leadership and organizational trust, satisfaction, and effectiveness. International Leadership Journal, 4(1), 1-19.

Kalshoven, K., \& Den Hartog, D.N. (2009). Ethical leader behaviour and leader effectiveness: The role of prototypicality and trust. International Journal of Leadership Studies, 5(2), 102-120.

Kalshoven, K., Den Hartog, D.N., \& De Hoogh, A.H.B. (2011). Ethical leadership a work questionnaire (ELW): Development and validation of a multidimensional measure. The Leadership Quarterly, 22(1), 51-69. https://dx.doi.org/10.1016/j. leaqua.2010.12.007

Kanungo, R.N. (2001). Ethical values of transactional and transformational leaders. Canadian Journal of Administrative Sciences, 18(4), 257-265. https://dx.doi org/10.1111/j.1936-4490.2001.tb00261.x
Kanungo, R.N., \& Medonca, M. (1996). Dimensions of ethical leadership. Thousand Oaks, CA: Sage Publications.

Kuntz, J.R.C, Kuntz, J.R., Elenkov, D., \& Nabirukhina, A. (2013). Characterizing ethical cases: A cross-cultural investigation of individual differences, organizational climate, and leadership on ethical decision making. Journal of Business Ethics, 113, 317-331. https://dx.doi.org/10.1007/s10551-012-1306-6

Lloyd, H.R., \& May, M.R. (2010). An ethics model to develop an ethical organisation. South African Journal for Human Resource Management, 8(1), 1-12. https:// dx.doi.org/10.4102/sajhrm.v8i1.218

Mafunisa, M.J. (2008). The role of codes of conduct in promoting ethical conduct in the SA public service. South African Journal of Labour Relations, 32(1), 81-92.

Mayer, D.M., Aquino, K., Greenbaum, R.L., \& Kuenzi, M. (2012). Who displays ethical leadership, and why does it matter? An examination of antecedents and consequences of ethical leadership. Academy of Management Journal, 55(1), 151-171. https://dx.doi.org/10.5465/amj.2008.0276

Mayer, D.M., Kuenzi, M., \& Greenbaum, R.L. (2010). Examining the link between ethical leadership and employee misconduct: The mediating role of ethical climate. Journal of Business Ethics, 96(5), 7-16. https://dx.doi.org/10.1007/ s10551-011-0794-0

Mels, G. (2003). A workshop on structural equation modelling with LISREL 8.54 for Windows. Chicago, IL: Scientific Software International.

Naidoo, G. (2012). The critical need for ethical leadership to curb corruption and promote good governance in the South African public sector. Journal of Public Administration, 47(3), 657-683.

Nasir, M., \& Bashir, A. (2012). Examining workplace deviance in public sector organisations of Pakistan. International Journal of Social Economics, 39(4) 240-253. https://dx.doi.org/10.1108/03068291211205677

Neubert, J.J., Carlson, D.S., Kacmar, L.M., Roberts, J.A., \& Chonko, L.B. (2009). The virtuous influence of ethical leadership behaviour: Evidence from the field. Journal of Business Ethics, 90, 157-170. https://dx.doi.org/10.1007/s10551-009-0037-9

Nunnally, J.C. (1978). Psychometric theory. New York: McGraw-Hill.

Pimental, J.R.C., Kuntz, J.R., \& Elenkov, D.S. (2010). Ethical decision-making: An integrative model for business practice. European Business Review, 22(4), 359-376. https://dx.doi.org/10.1108/09555341011056159

Rossouw, D., \& Van Vuuren, L. (2010). Business Ethics (4th edn.). Cape Town: Oxford University Press.

Simha, A., \& Cullen, J.B. (2011). Ethical climates and their effects on organisational outcomes: Implications from the past and prophecies for the future. Academy of Management Perspectives, 26(4), 20-34. https://dx.doi.org/10.5465/ amp.2011.0156

Sims, R.R. (1992). The challenge of ethical behaviour in organisations. Journal of Business Ethics, 11(7), 505-513. https://dx.doi.org/10.1007/BF00881442

Spangenberg, H., \& Theron, C.C. (2005). Promoting ethical follower behaviour through leadership of ethics: The development of the ethical leadership inventory (ELI) South African Journal of Business Management, 36(2), 1-19.

Van Zyl, E.S. (2012). Utilising human resource management in developing an ethical corporate culture. African Journal of Business Ethics, 6(1), 50-55. https://dx.doi. org/10.4103/1817-7417.104702

Victor, B., \& Cullen, J.B. (1988). The organisational bases of ethical work climates. Administrative Science Quarterly, 3(1), 101-125. https://dx.doi.org/10.2307/ 2392857

Yukl, G. (2013). Leading in organizations (8th edn.). Boston, MA: Pearson Education.

Yukl, G., Mahsud, R., Hassan, S., \& Prussia, G.E. (2011). An improved measure of ethical leadership. Journal of Leadership \& Organizational Studies, 20(10), 1-11.

Zhu, W., Avolio, B.J., Riggio, R.E., \& Sosik, J.J. (2011). The effect of authentic transformational leadership on follower and group ethics. The Leadership Quarterly, 22, 801-817. https://dx.doi.org/10.1016/j.leaqua.2011.07.004 